\title{
Electromagnetic Anomalies around The Wenchuan Earthquake and Their Relationship with Earthquake Preparation
}

\author{
Xuemin Zhang', ${ }^{1,2}$ and Xuhui Shen ${ }^{1}$ \\ ${ }^{1}$ Institute of Earthquake Science, CEA, Beijing 100036, China \\ ${ }^{2}$ Dipartimento di Fisica and INFN Sezione di Perugia, Via A. Pascoli, 06123 Perugia, Italy
}

Correspondence should be addressed to Xuemin Zhang, zhangxm96@126.com

Received 30 November 2010; Revised 9 June 2011; Accepted 9 June 2011

Academic Editor: Yun-tai Chen

Copyright ( $\odot 2011 \mathrm{X}$. Zhang and X. Shen. This is an open access article distributed under the Creative Commons Attribution License, which permits unrestricted use, distribution, and reproduction in any medium, provided the original work is properly cited.

Electromagnetic precursors before the Wenchuan earthquake on May 12, 2008 were collected and summarized on the basis of related published papers. The relationship between electromagnetic anomalies and different earthquake preparation stages was analyzed, and an entire seismic preparation process was constructed according to corresponding anomalies in different electromagnetic parameters. It is illustrated that stereo electromagnetic observation is useful in the understanding of earthquake preparation mechanism. It is inevitable that a lot of problems exist in anomaly distinguishing and coupling mechanism analysis, which needs further studies in future.

\section{Introduction}

The ground-based electromagnetic precursor observation has been developed in China for more than 40 years, which includes the observation of resistivity, electric field, geomagnetic field, electromagnetic emissions, and so on. When the Wenchuan earthquake took place on May 12, 2008, lots of electromagnetic stations were observing in normal operation condition. Until now, many papers have been published about this destructive event, in which many anomalies were found not only in ground-based information but also in space ionospheric detection (e.g., [1-4]). All these electromagnetic phenomena illustrated their relationship with this strong earthquake. It is regretful that most anomalies were obtained and published after the earthquake, so they did not play a great part in earthquake prediction. The main purpose of this paper is to summarize the electromagnetic anomalies and think about what we can learn from them.

\section{Electromagnetic Anomalies around the Wenchuan M8.0 Earthquake}

\subsection{Ground-Based Observation and Anomalies}

2.1.1. Resistivity Observation. Taking into account the big magnitude of the Wenchuan earthquake, 8 stations were selected in the distance of $500 \mathrm{~km}$, in which the Pixian station is the nearest one, $36 \mathrm{~km}$ to the epicenter (e.g., [2]). Figure 1 shows the time series in resistivity at three stations during 2003-2008, in which 1(a), and 1(b) show curves at two perpendicular directions, NE (North-East) and NW (NorthWest) at the Pixian station, 1(c), 1(d) at EW (East-West) and NW direction $(330 \mathrm{~km}$ to the epicenter) at the Ganzi station and 1(e), 1(f) at NW and NS (North-South) $(290 \mathrm{~km})$ at the Wudu station. Obvious anomalies were observed at these 3 stations, with the resistivity decreasing since 2006 relative to the normal level during 2003-2005, being about $-7.2 \%$ at NE direction at the Pixian station, $-4.5 \%$ at EW 


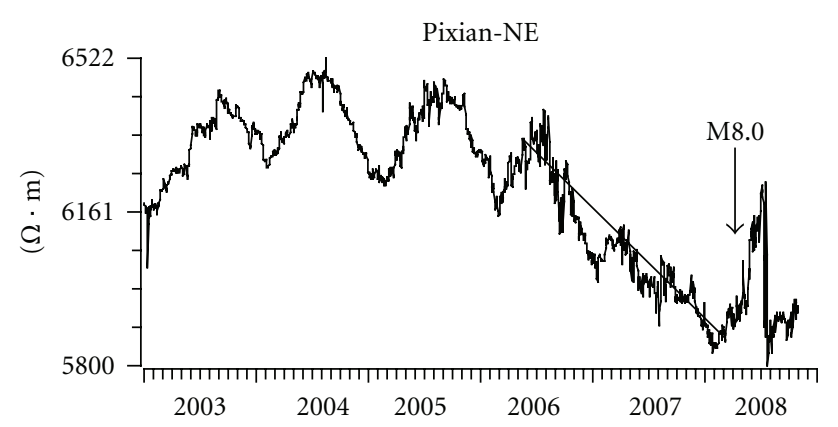

(a)

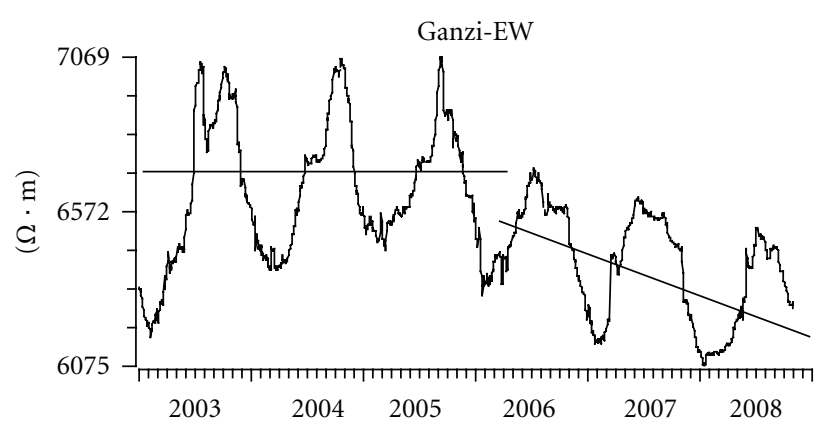

(c)

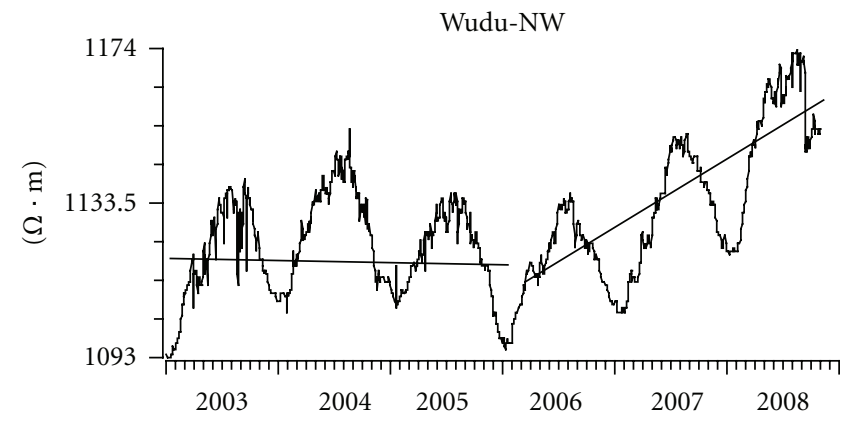

(e)

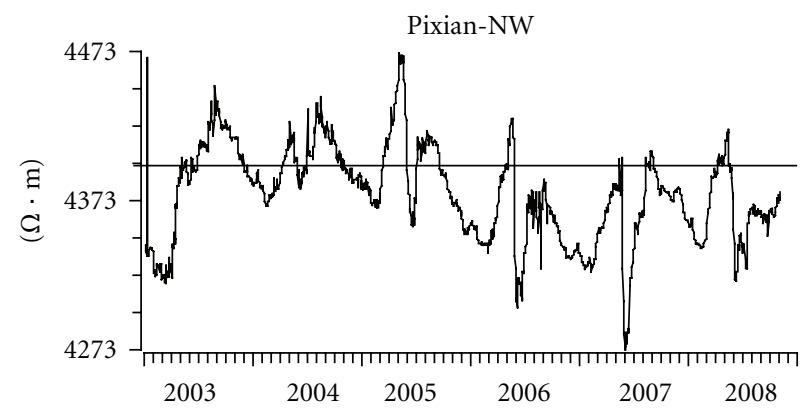

(b)

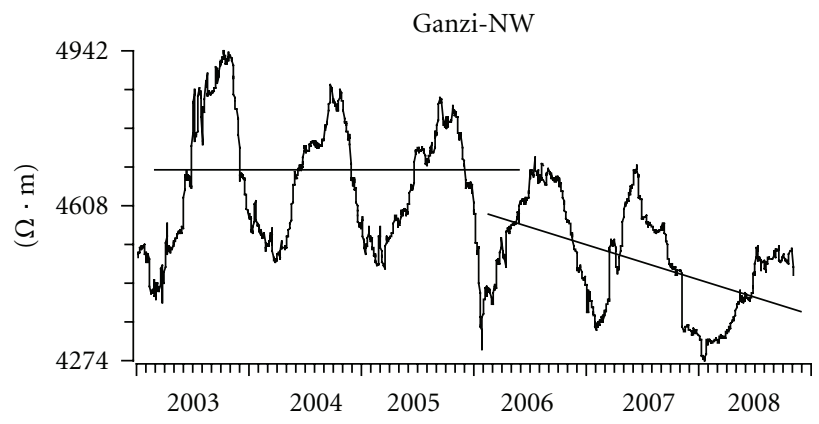

(d)

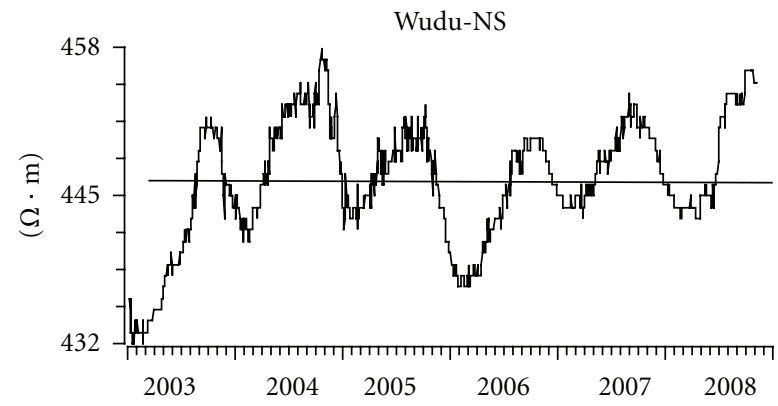

(f)

Figure 1: Apparent resistivity observation at the Pixian, Ganzi, and Wudu stations.

direction and $-3.3 \%$ at NW direction at the Ganzi station, $+2.5 \%$ at NW at Wudu stations. At the Ganzi and Wudu stations, the decreasing and increasing trends since 2006 were overlapped on their normal annual variation, but at the Pixian stations, its annual variation shape totally disappeared in 2007. Another difference among them is that, at the Pixian station, the earth apparent resistivity reached the minimum in January 2008, and then it began to increase, which was a turning point on near two-year decreasing trend, while at other two stations the anomaly trends did not show obvious turning point till the earthquake occurrence, which may indicate the difference of underground stress near epicenter with that at its outer area. During summer days with more rainfalls, these three stations all show higher resistivity than that in winter (Figure 1), which should be related to their underground electromagnetic structures (e.g., [5]). Prior to the Wenchuan earthquakes, they showed different variation trends, with apparent resistivity decreasing at Pixian and Ganzi stations, but increasing at the Wudus.
Pixian is just located at the east of the epicenter, Wudu at its northeast, and Ganzi at its west (Figure 2). Based on the focal mechanism of the Wenchuan earthquake (http://earthquake.usgs.gov/earthquakes/eqinthenews/2008/ us2008ryan/\#summary, Figure 2), Pixian and Ganzi were under the condition of compressive stress and Wudu was under tensional stress, which may lead to their differences in resistivity observation. Another phenomenon should be noticed here that not all observing directions showed anomalies in a station. For example, at the Pixian station, NE observing direction, parallel to the Wenchuan seismic faults (e.g., [6]; Figure 2), detected anomalous signals, while resistivity at another perpendicular direction NW, did not show obvious anomaly.

Before the Wenchuan earthquake, all the stations in $500 \mathrm{~km}$ to the epicenter did not show imminent anomalies in resistivity observation. As presented in Figure 1, the resistivity at Pixian changed its decreasing variation trend into increase since January 2008, and then in February to 


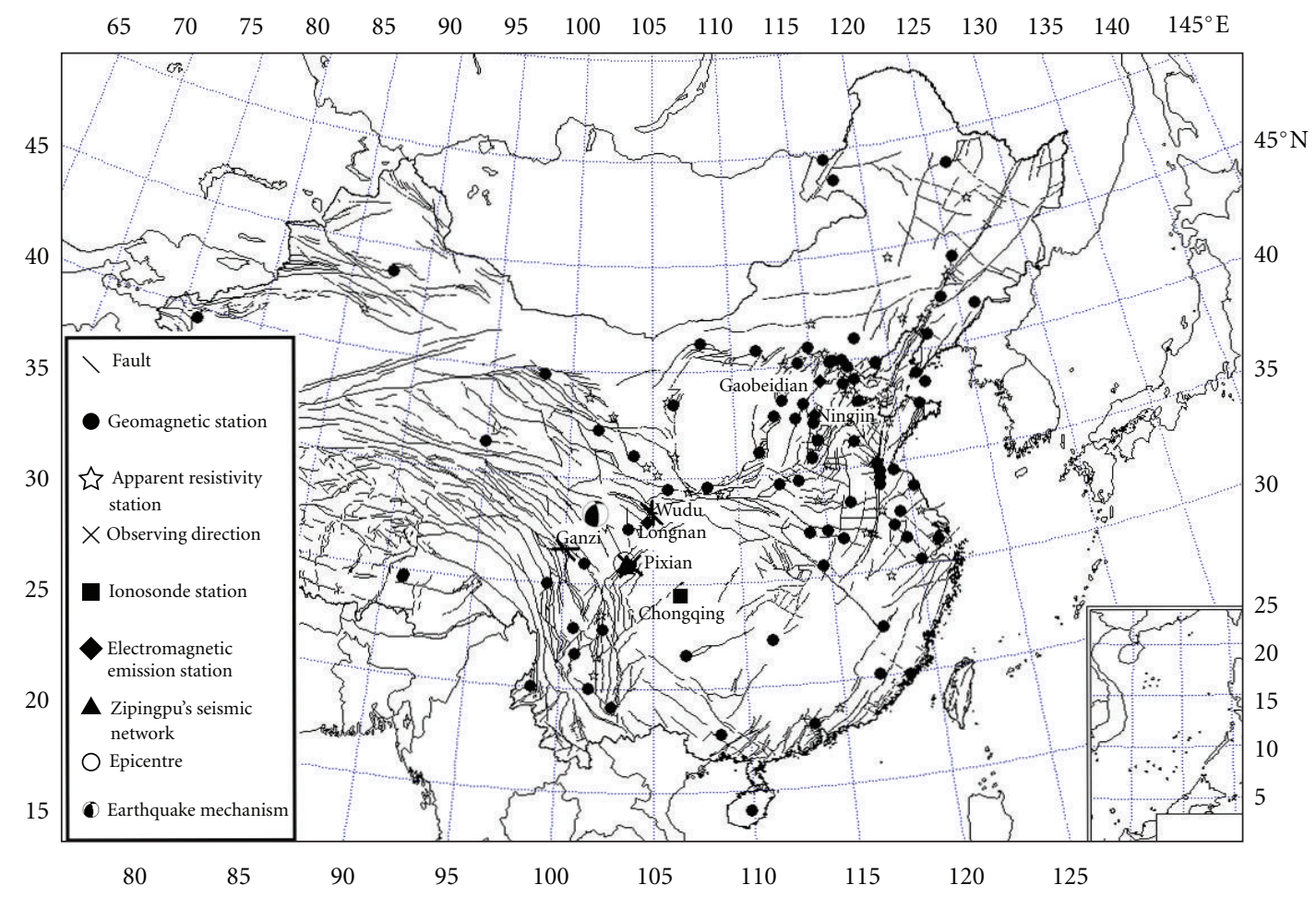

FIGURE 2: The location of the electromagnetic stations related to the Wenchuan earthquake study.

May, it maintained steady increase. Other stations also kept their own variation trend. From February to May, during more than 3 months, it is difficult to predict accurately when the earthquake will take place based only on this parameter.

2.1.2. Electromagnetic Emissions. The ELF electric field and magnetic field began to be observed since September, 2007 at the Longnan station in a distance of $305 \mathrm{~km}$ to Wenchuan epicenter (Figure 2). By calculating the autospectral density of each component data during January to June, 2008, Gao et al. found that significant anomalies occurred since May 1 in $39 \mathrm{~Hz}$ and $1 \mathrm{~Hz}$ magnetic field and electric field spectra, with 3 orders of magnitude enhancement relative to normal level [4].

Ding installed DC-II electromagnetic emission detectors in wells in order to avoid the disturbances at surface [8]. The detector has three frequency bands: $1 \mathrm{mHz}-1 \mathrm{~Hz}, 1-10 \mathrm{~Hz}$, and $10-20 \mathrm{~Hz}$. At the Jinhe station in distance of $35 \mathrm{~km}$ to the epicenter, the emissions increased since March 2007 at $1 \mathrm{~m} \mathrm{~Hz}-1 \mathrm{~Hz}$ and continued to the earthquake occurrence, while lots of EM emissions were detected from January to March 2008 at $1-10 \mathrm{~Hz}$ band.

The Gaobeidian and Ningjin stations are located in Hebei province (Figure 2), China, $1440 \mathrm{~km}$ and $1350 \mathrm{~km}$ from the Wenchuan epicenter, respectively. At these two stations, the electromagnetic emissions were observed at frequency $0.01-$ $1 \mathrm{~Hz}$. The preseismic emissions concentrated at two time segments, during the period October to December in 2007 and March to June in 2008 at the Gaobeidian station, while from January to July in 2008 at the Ningjin station (e.g., [9]).
2.1.3. Geomagnetic Field. Using the mean midnight value at local time of 00-03 O'clock on more than 100 stations of China Geomagnetic Observation Network (Figure 2), Zhang et al. obtained that the scale of positive magnetic field in epicentral area enlarged since April 20 relative to that on April 13, obviously broadened on April 30, recovered on May 2, broadened again on May 10, and recovered again on May 12 when M8.0 earthquake took place (e.g., [10]).

The mobile magnetic field observation in the Wenchuan epicentral area was carried out, respectively, in the first half year of 2004 and within 20 days after the Wenchuan earthquake. After comparison on these two time observations, it is found that at northeast of the epicenter, the intensity of total magnetic field decreased with amplitude of $-150 \mathrm{nT}$, and the magnetic declination changed from preseismic negative values into postseismic positive ones (e.g., [11]).

2.1.4. Thermal Infrared. Wei et al. studied the satellite remote-sensing images of thermal infrared 1st wave band $(10.3-11.3 \mu \mathrm{m})$ by FY-2C of China and found that the thermal infrared precursor appeared on March 18, 2008, 55 days before the earthquake, and then it experienced quite many and complex evolutionary stages with long time spanning until the earthquake occurrence. The first stage happened during March 18 to 26, a big temperatureincreasing area of $117 * 10^{4} \mathrm{~cm}^{2}$ being formed to the east of the Wenchuan earthquake. At the second stage during April 6-9, the thermal anomaly further enhanced and broadened. During the third stage at 16-20 April, the amplitude of temperature increments is $2-4^{\circ} \mathrm{C}$, smaller than that of 
$2-14^{\circ} \mathrm{C}$ in the former two stages. In the fourth stage at April 26-27, the thermal anomaly area is centered on the W-striking Wuhan-Chongqing along the Yangtze drainage. In the final stage during April 30-May 12, the anomalies moved southward gradually from North China terrace to South China terrace, showing a north to south process (e.g., [12]).

Using FY-2 satellite data same as those obtained by Wei et al. [12], Wu et al. [13] studied the thermal infrared images 20 days prior to the earthquake and found an anomalous thermal belt from southwest to northeast from India plate into China mainland during April 23-24. Wenchuan epicenter was located at the west of the middle segment of this belt. On May 3, it reoccurred again, and then it was intermittent due to the weather effects until the earthquake occurrence. Wu et al. and Wei et al. used the same data, but their results have significant differences, which may be related to the background selection and individual experiences in anomaly distinguishing.

Kang et al. analyzed the monthly and diurnal average data of OLR (Outgoing-Long-Wave-Radiation) by NOAA satellite, whose results showed that the biggest enhancement anomaly in OLR was distributed at $30^{\circ} \mathrm{N}, 102.5^{\circ} \mathrm{E}$ in 2007 , and it continuously occurred at $30-32.5^{\circ} \mathrm{N}, 102.5^{\circ} \mathrm{E}$ from February to April in 2008. As for the imminent precursors in OLR, it was found that OLR vorticity increased gradually from May 6 to 11, reaching the maximum on May 11, and then decreased since May 12 (e.g., [14]).

\subsection{Space Electromagnetic Anomalies}

2.2.1. GPS TEC. After Wenchuan earthquake, Zhao et al. [1] were the first to publish their results about the variation of GPS TEC. And then many authors presented their studies about that (e.g., [3, 15-18]). Most anomalies in TEC were found since April 29, and the significant anomaly occurred on May 9, 3 days before the earthquake. TEC anomaly on May 9 was distributed not only over the epicenter area but at its conjugate area in the south hemisphere [1].

2.2.2. Satellite Observation in Ionosphere. Zhang et al. studied the ion density, ion temperature, electron density, and electric field recorded by DEMETER satellite at $660 \mathrm{~km}$ height in ionosphere (e.g., [19-21]). The anomalies in the plasma parameters were mostly observed on May 9, which is same as that in GPS TEC. As for the electric field, it enhanced during 6-11 May at frequency lower than $5 \mathrm{kHz}$. Based on the high energy particle data recorded by DEMETER, Li et al. found that the spectra at $90-600 \mathrm{keV}$ energy band exhibited obvious differences on May 12 with those in other days around the earthquake [22]. He et al. calculated the SNR (signal-noise-ratio) of electric field at the transmitter frequencies, and obvious decrease in SNR was revealed a month before Wenchuan earthquake [23].

2.2.3. foF 2 by Ionosondes. There are more than 12 ionosondes in China mainland with continuous observation more than 30 years. Xu et al. analyzed the hourly values of $f_{\mathrm{oF}} 2$
TABLE 1: Summary of electromagnetic precursors before the Wenchuan earthquake.

\begin{tabular}{ll}
\hline $\begin{array}{l}\text { Type of electromagnetic } \\
\text { precursors }\end{array}$ & Parameters \\
\hline $\begin{array}{l}\text { Long-term anomaly more } \\
\text { than 1 year }\end{array}$ & $\begin{array}{l}\text { Apparent resistivity; OLR; } \\
\text { electromagnetic emissions in near } \\
\text { epicentral area } \\
\text { Geomagnetic field; electromagnetic } \\
\text { emissions; thermal infrared; SNR of } \\
\text { Midterm anomaly in a few } \\
\text { months }\end{array}$ \\
$\begin{array}{l}\text { Imminent anomaly in a few } \\
\text { GPS TEC; plasma parameters; VLF } \\
\text { electric field in ionosphere; foF2, }\end{array}$ \\
ELF electromagnetic field \\
Anomaly in a few hours
\end{tabular}

over ten observatories. Their results indicate that there were giant positive disturbances of $f_{\mathrm{oF}} 2$ around the epicentral zone on 9 May. $f$ oF2 was notably abnormal beyond upper bound (the maximum abnormality up to $65 \%$ at $17: 00 \mathrm{BJT}$ ) on May 9 at the Chongqing stations, and lasted three hours (e.g., [24, 25]).

According to the starting time and duration of anomalies exhibited above, we summarized the related information in Table 1. It can be seen that long-term and midterm precursors were observed dominantly at ground-based stations or thermal infrared by satellite, while imminent precursors occurred mostly in ionosphere. So what is the relationship among them? Is there a parameter that can cover the entire process? Are they related to each other? We will discuss thesa in the following part.

\section{Discussion}

In a sum of all electromagnetic precursors before the Wenchuan earthquake (Figure 3 ), the preparation process of this earthquake can be divided into four stages.

3.1. The Stage of Stress Accumulation. Based on the observation of earth resistivity, it can be concluded that the process of stress accumulation before the Wenchuan $M_{s} 8.0$ earthquake took more than 2 years (Figures 3; and 1) since 2006. Prior to the Tangshan M7.8 earthquake taking place in China on July 28, 1976, the apparent resistivity showed a consistent decrease at 10 stations in a region of $200 \mathrm{~km}$ around the epicenter, with a period of variation of 2-3 years and a maximum change of $-6 \%$ [26]. Qian et al. [27] had obtained the logarithm relationship between anomaly duration of resistivity and earthquake magnitude based on statistical analysis. By the equation [27], two years anomaly in earth resistivity means a future earthquake with magnitude above 7.0. During this stage, the parameters that are sensitive to underground stress and strain change should be paid more attention, such as the earth apparent resistivity. Moreover, most microfractures would be closed at this stage, so electromagnetic emissions are not active.

To understand the underground stress change, S-wave split is thought as a distinctive tool in recent years. Zhang 


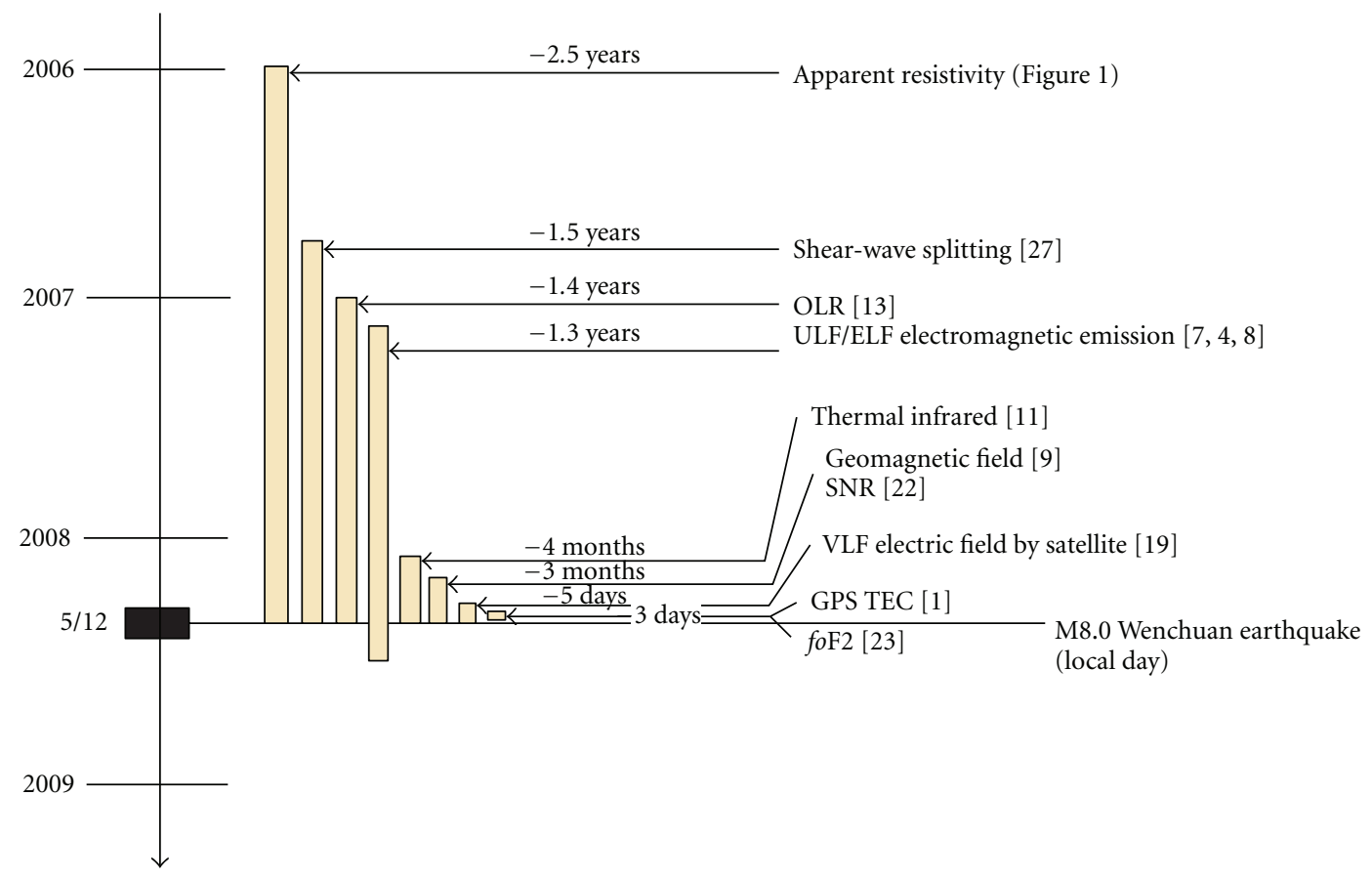

FIGURE 3: Time lines of the electromagnetic precursors of the 2008 Wenchuan earthquake.

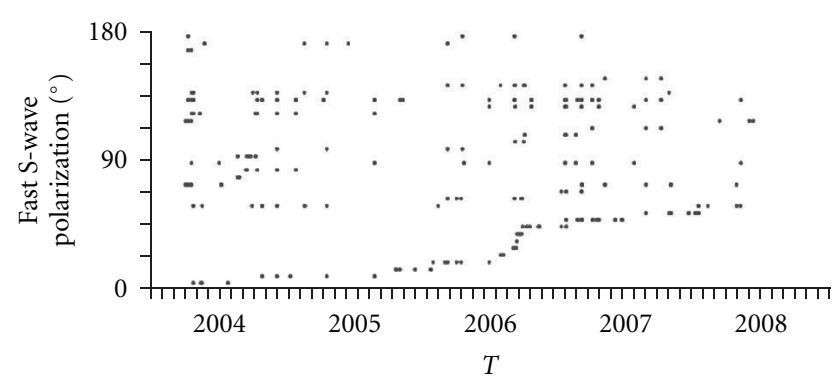

FIgURE 4: The fast shear-wave polarizations in Zipingpu region (from [7]).

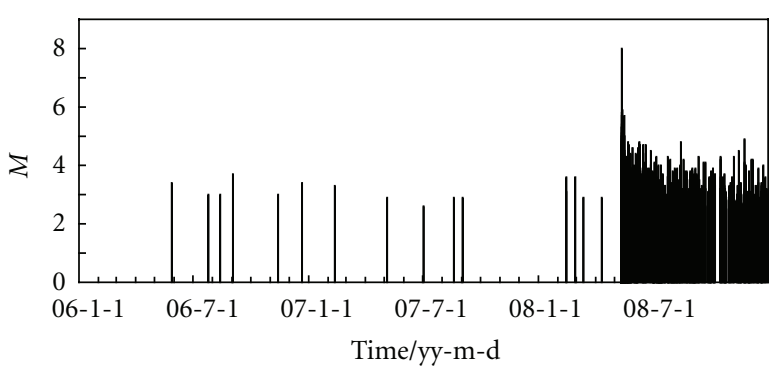

Figure 5: M-T image during 2006-2008 in the Wenchuan epicentral area $\left(30-32^{\circ} \mathrm{N}, 103-104^{\circ} \mathrm{E}\right)$.

et al. [7] studied the shear-wave splitting by SAM (Systematic analysis method) technique at 8 stations of Zipingpu Reservoir Digital Seismic Network (Figure 2) from August 17, 2004 to May 11, 2008. Their results show that the dominant polarization directions of fast shear waves are at NE or
NW direction, consistent with the strikes of active faults or regional principal compressive stress. On 5 stations mainly at the southeast of Wenchuan, the direction concentrated to NW, while on 2 stations at northeast of the epicenter, the main direction is NE, which reflects the difference in regional stress. Compared with the Earth resistivity, the dominant stress direction is corresponding to the decreasing direction at the Pixian and Ganzi stations. Another interesting thing is that the anomaly in resistivity was more easily observed at the perpendicular direction of compressive stress; for example, resistivity at $\mathrm{NE}$ on Pixian station decreased significantly under the principal compressive stress of NW direction, while at NW it changed a little.

Seen from the temporal distribution (Figure 4; [7]), the polarization direction began to concentrate to NE and NW since November 2006, which was lagged a few months after the beginning time of anomalies in Earth resistivity observation, but basically coincided with each other. The results of Zhang et al. [7] verified the process of stress loading and energy accumulation during 2006-2008 from another side.

During this stress accumulation stage, some other phenomena such as OLR and electromagnetic emissions also began to emerge (Figure 3 ).

3.2. The Locked Stage. In rock failure tests, it always experiences a few stages before failure, such as pore compressibility, elastic deformation, volume expansion, and then failure (e.g., [28]). After a long-time stress-loading process, the micro fractures in rock will be closed completely and the tectonic activity reduced to the lowest. In order to reflect the underground stress state in meizoseismal area, Figure 5 
presents the M-T diagram of earthquakes larger than $M_{L} 2.5$ in the region of $30-32^{\circ} \mathrm{N}$ and $103-104^{\circ} \mathrm{E}$. It shows that during 2006-2007, the earthquakes took place occasionally, but from September 2007 to January 2008, no earthquake occurred in this region. During this stage, nearly no newly born electromagnetic anomaly was detected.

3.3. The Stress Deblocking or Rock Expansion Stage. Since February 2008, the resistivity at the Pixian station its decreasing trend into an increasing one, and at the same time the OLR anomaly region began to expand. In rock test about thermal infrared radiation [29], the temperature increases wholly at stress blocking stage. However, at stress deblocking stage, positive infrared abnormity strip with complex shape would emerge in the discontinuous locations of an echelon faults and disconnected faults. Most infrared thermal anomalies have been observed since February 2008 and experienced multiple-replication process of enhancementweakening-enhancement, which is similar to the phenomena at this stage in the rock test. Accompanying the stress deblocking, small earthquakes take place now and then (Figure 5). At this stage, the number of microfractures would increase, and ULF electromagnetic emissions are radiated (Figure 3). From the observing results, lots of EM emissions occurred, even at stations in a long distance (See also Section 2.1.2).

3.4. The Impeding Earthquake Stage. Since April 26, the electromagnetic precursors grew in number and enhanced than that in former time. Moreover, on May 9, a lot of ionospheric perturbations were detected, which indicates the impending earthquake. Based on statistical analysis (e.g., [30]), most ionospheric anomalies occurred in a few days or hours before the main shocks. So the occurrence of ionospheric anomalies could be taken as an indicator for impeding stage.

Among all the electromagnetic parameters shown above, there is no one that can penetrate throughout and show different shapes at different seismic developing stages, but combination of abundant electromagnetic observation around the Wenchuan earthquake at surface and in space presents a complete picture of earthquake preparation process. Tsai et al. [31] studied the precursory phenomena in lithosphere, atmosphere, and ionosphere which were associated with the 1999 Chi-Chi earthquake in Taiwan, and they obtained three-stage information such as increase of $\mathrm{P}$ wave travel time occurring 6 years before the event; surface deformation, $b$ value and geomagnetic annual change rate $2-3$ years before; electromagnetic precursors 2-3 months before and after the earthquake. Compared with their results, it is similar that precursors concentrated at two time segments, 1-2 years and a few months before the Wenchuan earthquake (Figure 3), which illustrate that electromagnetic precursory phenomena are sensitive in earthquake preparation process. At different stage, different parameter will play different role due to the change of underground stress condition. If we want to find longer-term anomaly just as Tsai et al., other geophysical parameters are needed. The relationship among different parameters in electromagnetic field may not be very close, but they are connected with the seismic preparation process very well. Therefore, multiparameter data collecting and comprehensive analysis are important in earthquake study.

In earthquake prediction, three key elements are concluded: time, place, and magnitude. The most important and difficult one is "when", the occurrence time of future earthquake. Because most data referred above was processed after the Wenchuan earthquake, the studied time segment and area were always limited by the authors according to the earthquake occurrence time and its location. So it should be made clear that seismic anomaly may not be as simple as shown in this paper. For example, prior to the Wenchuan earthquake, the ionospheric perturbations are the latest and significant anomaly. Can it be used in real earthquake prediction if it was really found just before the earthquake? The answer is definitely "no." It is believed that similar ionospheric anomaly just as that on May 9 did not occurr only one time and only on this day before the Wenchuan earthquake whether in $f_{\mathrm{oF}}$, GPS TEC, or other plasma parameters. Actually, whether some anomalies are related to or resulted from this earthquake is still uncertain. So, two problems need to be about. The first one is the nonuniqueness and uncertainty of the anomaly, which will cause lots of false prediction. The second one is the coupling mechanism among earthquake and electromagnetic precursors, which is also the basis to solve the first problem. We still take the example of anomalies on May 9. The resistivity changes a little on that day, thermal infrared not showing special enhancement, while the number and intensity of electromagnetic emissions also present no obvious increase, so what led to the large perturbations in ionosphere? What is the source of the variation in ionosphere? Ground-based electromagnetic observation cannot explain those sudden variations in ionosphere on May 9, because they were not corresponding to each other at the occurrence time. To find the coupling mechanism of lithosphere and ionosphere, we have a long way to go.

\section{Conclusion}

Occurrence of an earthquake is related to not only the condition around hypocenter, but the regional stress field, and environmental factors in interior Earth and outer space. The electromagnetic field is one of the natural mediums that connect numerous factors during earthquake preparation. As shown in this paper, different kinds of electromagnetic anomalies occurred at different earthquake developing stages, and they exhibited close relationship with the Wenchuan earthquake in position and time. The groundbased and space electromagnetic observation before the Wenchuan earthquake demonstrated that building stereo electromagnetic observation system is meaningful for earthquake research.

Earthquake prediction is still a big problem in the world. Based on the previous studies on electromagnetic anomalies around the Wenchuan earthquake, we learnt some experiences and revealed some problems. It is inspiring that a lot of 
electromagnetic precursors were detected by ground-based and satellite observation before the Wenchuan earthquake, thanks to the development of observation technology, which remains a gleam of hope for earthquake prediction. However, the anomalies were diverse and always reiterative for several times, which all bring big difficulties in earthquake prediction. Moreover, there are still a lot of questions left in the coupling mechanism study, on which rock test and digital analogue should be strengthened in future, and more parameters in other geophysical field should be taken into consideration.

\section{Acknowledgments}

This paper is funded by the Key Earthquake Science Research Fund (201008007), International Cooperation Project (2009DFA21480). The author X. Zhang thanks the Chinese Scholarship Council and CEA for supporting her study in INFN, Italy.

\section{References}

[1] B. Zhao, M. Wang, T. Yu et al., "Is an unusual large enhancement of ionospheric electron density linked with the 2008 great Wenchuan earthquake?" Journal of Geophysical Research A, vol. 113, Article ID A11304, p. 6, 2008.

[2] X. Zhang, M. Li, and H.-P. Guan, "Anomaly analysis of earth resistivity observations before the Wenchuan earthquake," Earthquake, vol. 29, no. 1, pp. 108-115, 2009 (Chinese), (with English abstract).

[3] J. Y. Liu, Y. I. Chen, C. H. Chen et al., "Seismoionospheric GPS total electron content anomalies observed. before the 12 May $2008 M_{w} 7.9$ Wenchuan earthquake," Journal of Geophysical Research A, vol. 114, Article ID A04320, p. 10, 2009.

[4] S. D. Gao, J. Tang, X. B. Du et al., "The change characteristics of electromagnetic field before to after Wenchuan Ms 8.0 earthquake," Chinese Journal of Geophysics, vol. 53, no. 3, pp. 512-525, 2010.

[5] J. Lu, S. Xue, F. Qian et al., "Unexpected changes in resistivity monitoring for earthquakes of the Longmen Shan in Sichuan, China, with a fixed Schlumberger sounding array," Physics of the Earth and Planetary Interiors, vol. 145, no. 1-4, pp. 87-97, 2004.

[6] H. Li, Z. Wang, X. Fu et al., "The surface rupture zone distribution of the Wenchuan earthquake(Ms 8.0) happened on May 12th, 2008," Geology in China, vol. 35, no. 5, pp. 803813, 2008 (Chinese), (with English abstract).

[7] Y. J. Zhang, Y. Gao, Y. T. Shi, and L. X. Tai, "The shear-wave splitting study of Sichuan Zipingpu reservoir region," Chinese Journal of Geophysics, vol. 53, pp. 2091-2101, 2010.

[8] Y. J. Ding, "Electromagnetic disturbances and Wenchuan earthquake," Recent Developments in World Seismology, no. 7, pp. 8-18, 2009 (Chinese), (with English abstract).

[9] M. Li, J. Lu, Y. Chang, and X. Liu, "ULF electromagnetic anomaly observed at Gaobeidian and Ningjin seismic stations before Wenchuan 8.0 earthquake," Recent Developments in World Seismology, no. 7, pp. 76-82, 2009 (Chinese), (with English abstract).

[10] J. G. Zhang, X. C. Liu, T. M. Tang, and J. Z. Ma, "Research on dynamic evolution characteristics of geomagnetic field in Chinese mainland before and after Wenchuan Ms 8.0 earthquake," Journal of Seismological Research, vol. 32, no. 3, pp. 231-234, 2009 (Chinese), (with English abstract).

[11] C. L. Gu, Y. Zhang, R. G. Xu, and L. Wang, "Analysis of the variation characteristic in the lithospheric geomagnetic field before and after earthquakes," Progress in Geophysics, vol. 25, no. 2, pp. 472-477, 2010 (Chinese), (with English abstract).

[12] L. Wei, J. Guo, J. Liu, Z. Lu, H. Li, and H. Cai, "Satellite thermal infrared earthquake precursor to the Wenchuan Ms 8.0 earthquake in Sichuan, China, and its analysis on geo-dynamics," Acta Geologica Sinica, vol. 83, no. 4, pp. 31-54, 2009 (Chinese), (with English abstract).

[13] L. X. Wu, S. J. Liu, Y. H. Chen, B. D. Ma, and L. L. Li, "Satellite thermal infrared and cloud abnormities before Wenchuan earthquake," Science \& Technology Review, vol. 26, no. 10, pp. 32-36, 2008 (Chinese), (with English abstract).

[14] C. Kang, Y. Zhang, D. Liu, and F. Jing, "Long-wave-radiation patterns prior to the Wenchuan M 8.0 earthquake," Earthquake, vol. 29, no. 1, pp. 116-120, 2009 (Chinese), (with English abstract).

[15] T. Yu, T. Mao, Y. Wang, and J. Wang, "Study of the ionospheric anomaly bafore the Wenchuan earthquake," Chinese Science Bulletin, vol. 54, no. 6, pp. 1086-1092, 2009 (Chinese), (with English abstract).

[16] J. Lin, Y. Wu, F. Zhu, X. Qiao, and Y. Zhou, "Wenchuan earthquake ionosphere TEC anomaly detected by GPS," Chinese Journal of Geophysics, vol. 52, no. 1, pp. 297-300, 2009.

[17] S. A. Pulinets, V. G. Bondur, M. N. Tsidilina, and M. V. Gaponova, "Verification of the concept of seismoionospheric coupling under quiet heliogeomagnetic conditions, using the Wenchuan (China) earthquake of May 12, 2008, as an example," Geomagnetism and Aeronomy, vol. 50, no. 2, pp. 231-242, 2010.

[18] Y. Zhou, Y. Wu, X. Qiao, F. Zhu, and J. Yang, "Anomalous variations of ionospheric VTEC before Ms 8.0 Wenchuan earthquake," Chinese Journal of Geophysics, vol. 53, no. 3, pp. 556-566, 2010.

[19] X. Zhang, X. Shen, J. Liu, X. Ouyang, J. Qian, and S. Zhao, "Analysis of ionospheric plasma perturbations before Wenchuan earthquake," Natural Hazards and Earth System Science, vol. 9, no. 4, pp. 1259-1266, 2009.

[20] X. Zhang, X. Shen, X. Ouyang et al., "Ionosphere VLF electric field anomalies before Wenchuan M 8 earthquake," Chinese Journal of Radio Science, vol. 24, no. 6, pp. 1024-1032, 2009 (Chinese), (with English abstract).

[21] X. Zhang, X. Shen, J. Liu, X. Ouyang, J. Qian, and S. Zhao, "Ionospheric perturbations of electron density before the Wenchuan Earthquake," International Journal of Remote Sensing, vol. 31, no. 13, pp. 3559-3569, 2010.

[22] X. Q. Li, Y. Q. Ma, H. Y. Wang et al., "Observation of particle on space electro-magnetic satellite during Wenchuan earthquake," Chinese Journal of Geophysics, vol. 53, no. 10, pp. 2337-2344, 2010.

[23] Y. He, D. Yang, H. Chen, J. Qian, R. Zhu, and M. Parrot, "SNR changes of VLF radio signals detected onboard the DEMETER satellite and their possible relationship to the Wenchuan earthquake," Science in China D: Earth Sciences, vol. 52, no. 6, pp. 754-763, 2009.

[24] T. Xu, Y. Hu, J. Wu, Z. Wu, Y. Suo, and J. Feng, "Giant disturbance in the ionospheric F2 region prior to the $M 8.0$ Wenchuan earthquake on 12 May 2008," Annales Geophysicae, vol. 28, pp. 1533-1538, 2010.

[25] T. Xu, Y. Hu, J. Wu et al., "Abnormal perturbations in the ionospheric F2 region before Wenchuan earthquake on 12 
May 2008," Science China Earth Sciences, vol. 53, no. 11, pp. 1671-1674, 2010.

[26] J. Qian, "Regional study of the anomalous change in apparent resistivity before the Tangshan earthquake $(M=7.8,1976)$ in China," Pure and Applied Geophysics PAGEOPH, vol. 122, no. 6, pp. 901-920, 1984.

[27] F. Y. Qian, Y. L. Zhao, M. M. Yu, Z. X. Wang, X. W. Liu, and S. M. Chang, "Electrical resistivity anomalies before earthquakes," Scientia Sinica B, vol. 12, no. 9, pp. 831-839, 1982 (Chinese), (with English abstract).

[28] Y. Chen, "A preliminary study on the frature of rocks under uniaxial compression," Acta Geophysica Sinica, vol. 29, pp. 306-315, 1976 (Chinese), (with English abstract).

[29] L. Wu, S. Liu, Y. Wu, and Y. Li, "Remote sensing-rock mechanics (I)-laws of thermal infrared radiation from fracturing of discontinuous jointed faults and its meanings for tectonic earthquake omens," Chinese Journal of Rock Mechanics and Engineering, vol. 23, no. 1, pp. 24-30, 2004.

[30] S. A. Pulinets, A. D. Legen'ka, T. V. Gaivoronskaya, and V. Kh. Depuev, "Main phenomenological features of ionospheric precursors of strong earthquakes," Journal of Atmospheric and Solar-Terrestrial Physics, vol. 65, no. 16-18, pp. 1337-1347, 2003.

[31] Y. B. Tsai, J. Y. Liu, K. F. Ma et al., "Precursory phenomena associated with the 1999 Chi-Chi earthquake in Taiwan as identified under the iSTEP program," Physics and Chemistry of the Earth, vol. 31, no. 4-9, pp. 365-377, 2006. 

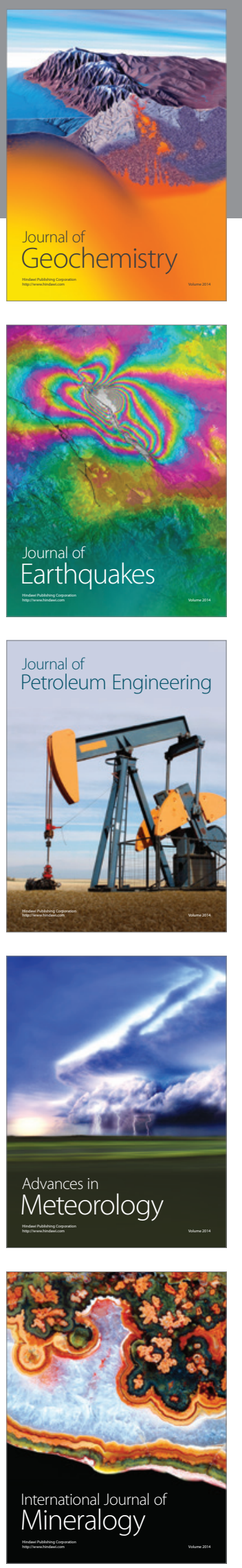
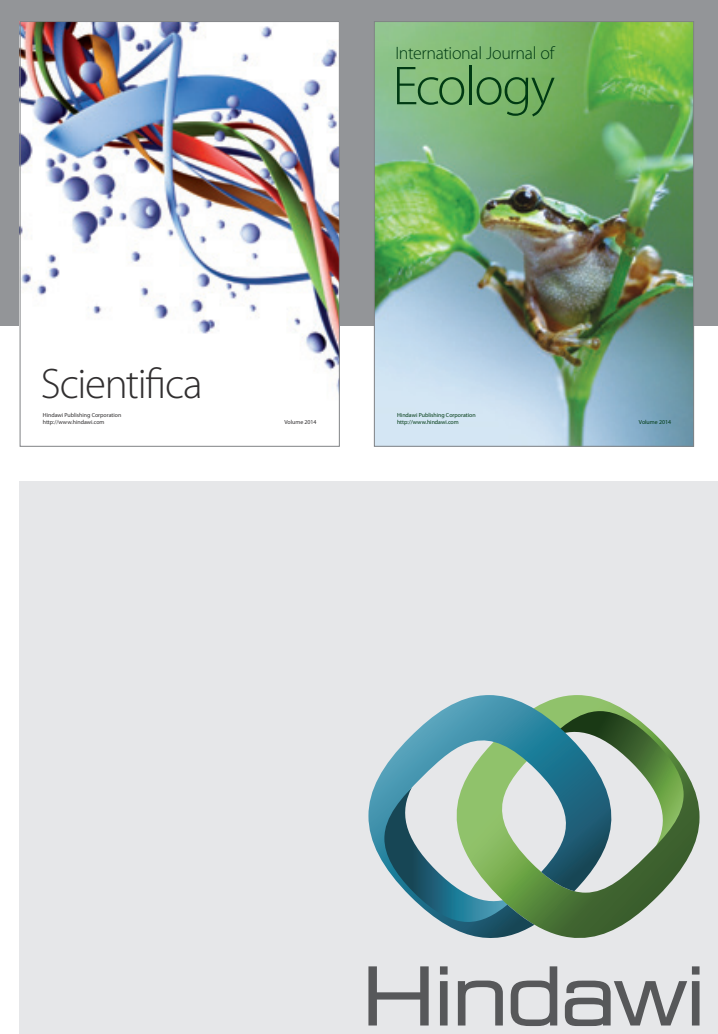

Submit your manuscripts at http://www.hindawi.com
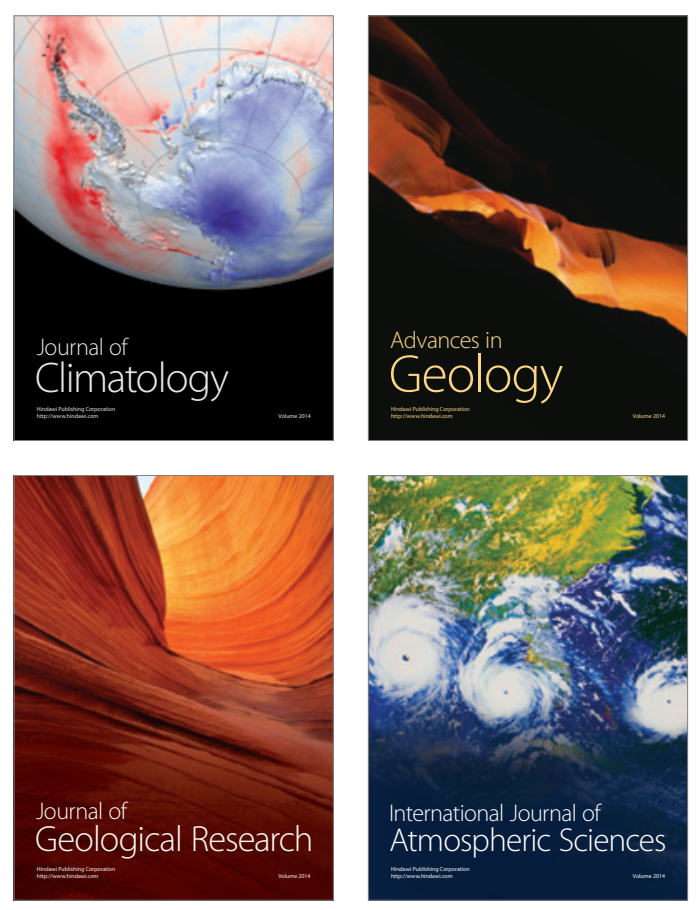
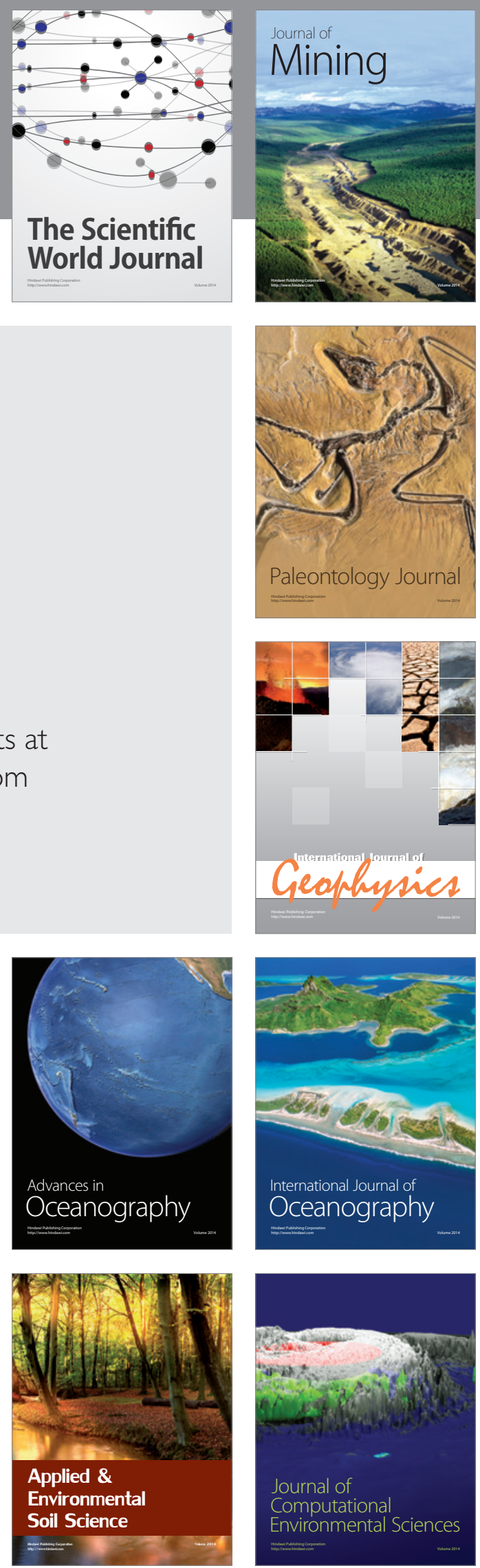